\title{
Complex modification effect of linseed cake as an agricultural waste filler used in high density polyethylene composites
}

\author{
Mateusz Barczewski ${ }^{1}$. Olga Mysiukiewicz ${ }^{1}$ (D) $\cdot$ Arkadiusz Kloziński $^{2}$
}

Received: 9 February 2018 / Accepted: 23 June 2018 / Published online: 31 July 2018

(c) The Author(s) 2018

\begin{abstract}
Linseed cake (LC) is a by-product of agricultural industry which does not have any large-scale industrial applications. The possibilities of its utilization as filler with plasticizing ability for high density polyethylene (HDPE)-based composites have been investigated. Composites containing 5, 10, 20 and $30 \mathrm{wt} \%$ of the waste filler have been prepared using a melt mixing method. The influence of the LC on the mechanical and thermomechanical properties of the composites, as well as their water absorption and morphology, have been evaluated by the following methods: static tensile test, impact strength assessment using Dynstat method, hardness measurements, differential scanning calorimetry, dynamic mechanical thermal analysis, scanning electron microscopy observations, measurements of Vicat's softening temperature and water uptake test. Application of different measuring techniques allows for describing complex modification effects of the composites' properties changes induced by the presence of lignocellulosic filler with high oil content. The results of the study proved a pronounced influence of LC on high density polyethylene-based composites, especially a plasticizing effect of crude linseed oil contained by the waste filler particles. LC also has been assumed to affect the polymeric matrix crystallization process. It was found that complex modification of polyethylene results from simultaneously occurring different phenomena including: plasticization of the HDPE by linseed oil, improved crystallinity of the semicrystalline matrix, presence of the rigid lignocellulosic particles dispersed in polymer and accumulation of the oil in the interfacial regions.
\end{abstract}

Keywords Polyethylene $\cdot$ Natural composites $\cdot$ Waste management $\cdot$ Natural filler $\cdot$ Mechanical properties

\section{Introduction}

At the beginning of the XXI century, in the era of global warming and rapidly growing world's population, terms of circular economy and sustainability became crucial concerns for business, governments and researchers alike. The idea of circular economy, which embraces the balance between environment and economy, can be defined as "a system in which resource input and waste, emission, and energy

Mateusz Barczewski

mateusz.barczewski@put.poznan.pl

$\bowtie$ Olga Mysiukiewicz

olgamysiukiewicz@gmail.com

1 Faculty of Mechanical Engineering and Management, Institute of Materials Technology, Poznan University of Technology, Piotrowo 3, 61-138 Poznan, Poland

2 Faculty of Chemical Technology, Institute of Chemical Technology and Engineering, Poznan University of Technology, Berdychowo 4, 60-965 Poznan, Poland leakage are minimized by slowing, closing and narrowing material and energy loops" [1]. One of the ways to achieve this goal is to treat waste products coming from one process as valuable resources for the industry.

Another highly appreciated method to decrease the environmental impact of manufactured goods is to substitute conventional, non-renewable materials with their sustainable counterparts [2]. In the polymer processing industry, natural-based fillers are a frequently used alternative for conventional reinforcing and modifying agents because of their low carbon footprint, environmental friendliness and satisfactory properties $[3,4]$. Nevertheless, planting and processing plants to obtain fillers for polymeric composites is also energy, water and resources-consuming [5]. Ecologically wise, it can be more advantageous to incorporate a plant-based waste product into a polymeric matrix and thus create an environmentally friendly composite.

Linseed (Linum usitatissimum) is a versatile plant cultivated around the world, mostly for fibers and oil-rich seeds. Linseed cake (LC) is a by-product of the linseed oil 
production by means of cold pressing. It comprises lignocellulose, proteins, oligosaccharides and up to $37 \mathrm{wt} \%$ of crude oil which cannot be extracted using mechanical methods [6]. Despite the fact that this substance is produced every year in large quantities (417,000 $\mathrm{t}$ in 2016, EU countries) [7], it is mostly used for feeding livestock, as a bait for fish or as a dietary supplement for humans $[8,9]$. From both ecologic and economic points of view, it is highly advantageous to implement this lignocellulose and oil-rich waste product in industrial processes, as well.

Linseed oil comprises about $90 \%$ unsaturated fatty acids $[10,11]$. The double bonds of the triglycerides can react with oxygen, creating oxirane or epoxy groups [12, 13]. Different vegetable oils modified this way are commonly used by different branches of the industry, usually as chemical substrates for the synthesis of new compounds [12]. They can also find an application in the plastics industry, for example, in the production of polyurethanes [14]. Epoxidized soybean oil have been successfully used as a plasticizing agent for poly(vinyl chloride) as well as poly(lactic acid) (PLA) [15]. As Al-Mulla et al. [16] proposed in their work, epoxidized palm oil reacts chemically with PLA, hence it can be used as a coupling agent for polymeric composites. As we have already mentioned, LC is an easily available agricultural waste product which lacks an industrial application. It contains both lignocellulose and crude vegetable oil, hence it supposedly could serve as an additive for polymeric composites.

Lignocellulose is a building material of plant cells' walls; therefore, it is abundant in wood flour, hemp or kenaf fiber and many more plant-derived materials used as fillers for polymeric composites [3, 17]. As lignocellulose is stiffer than polymeric matrix, it usually enhances the elastic modulus and the tensile strength of the composites. Lignocellulose-rich fillers has been successfully used as a reinforcement for polymeric composites applied in automotive industry [18]. Despite the beneficial effect of natural fillers on the mechanical behavior of the polymeric composites, an increased stiffness is usually accompanied with high brittleness. The main goal of this work is to determine the possibility of partially suppressing the composites brittleness caused by lignocellulosic fillers by means of the application of LC as an organic material with high content of fat, which provides a plasticizing effect on high density polyethylene matrix. Plasticizing effect of the oil migrating from the natural filler into HDPE was evaluated on the basis of thermal, thermomechanical analyses and structural observations related to changes of mechanical properties induced by incorporation of the various amounts of LC.

\section{Experimental}

\section{Materials and methods}

High density polyethylene Hostalen GC 7260 by Basell Orlen Polyolefins (Poland) (melt flow index, MFI of $8 \mathrm{~g} / 10 \mathrm{~min}$, density of $0.96 \mathrm{~g} / \mathrm{cm}^{3}$ ) was chosen as the matrix of the composites.

Linseed cake was purchased from a local supplier (Poland, the Greater Poland region). To obtain a uniform filler particle size distribution, one fraction of the particles was separated using an Analysette 3 Fritsch vibrational siever (Germany) equipped with a $1000 \mu \mathrm{m}$ mesh. The characterization of the particle size distribution of the natural powder-like filler was evaluated using a laser particle sizer Fritsch ANALYSETTE 22 (Germany) apparatus. The particle size distribution and its derivative are presented in Fig. 1a. A microscopic image of the sieved LC particles is presented in Fig. 1b, as well. Digital images were acquired using a Nikon Eclipse E400 (Japan) microscope equipped with an Opta-Tech digital camera
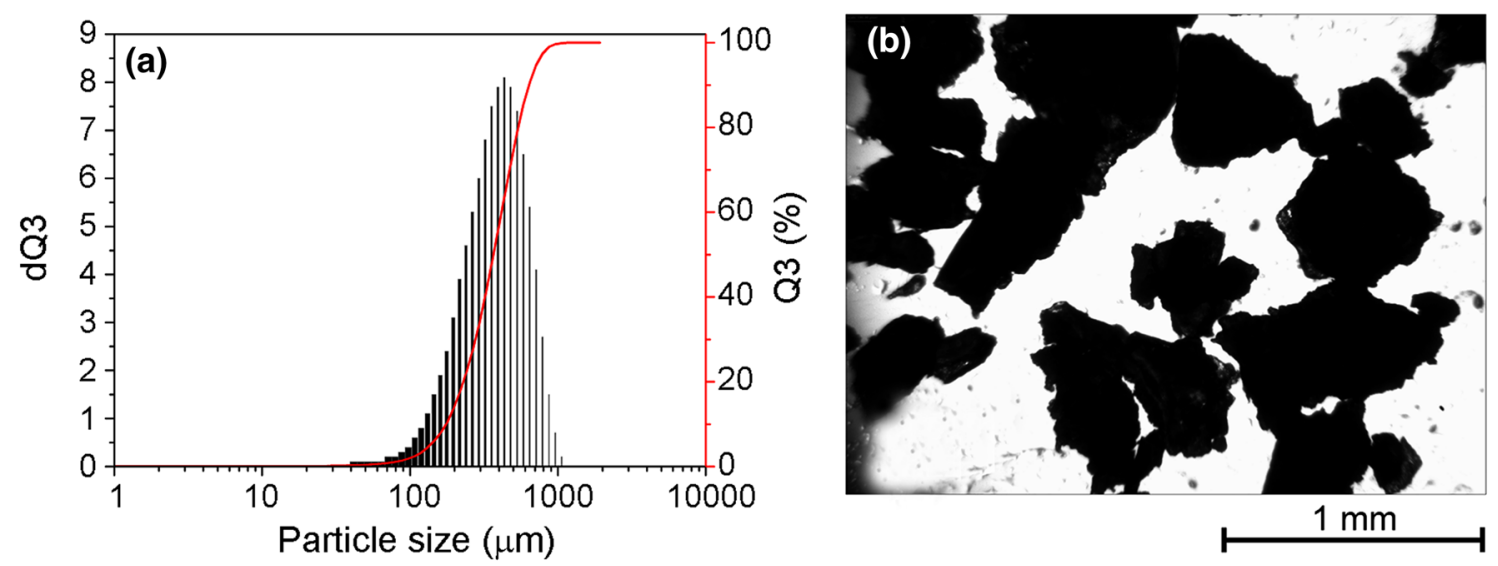

Fig. 1 a Linseed cake particle size distribution and $\mathbf{b}$ microscopic image of its particles (magnification of $\times 20$ ) 
with a magnification of $20 \times$. It can be seen that the used $\mathrm{LC}$ is a typical particle shaped filler, the calculated $L / D$ mean value of the particles was 1.67.

The linseed oil content of the LC was determined using standard Soxhlet method using Büchi Universal Extraction System B-811 (Switzerland), operating with petroleum ether as a solvent and a total extraction time of $150 \mathrm{~min}$. The measured value of the oil content in the filler was $28.7 \mathrm{wt} \%$.

The moisture content of the filler was determined on the basis of measurements carried out with an AXIS ATS 60 (Poland) moisture analyzer. During the test, a temperature of $105 \pm 1{ }^{\circ} \mathrm{C}$ was applied, and the duration of the individual analysis was $10 \mathrm{~min}$. Measurements were conducted for the filler before the drying process. It was found that the moisture content in the natural filler was $5.23 \%$. Therefore, it was necessary to remove excessive moisture, the fractioned LC as well as HDPE-LC physical mixtures were dried at $70{ }^{\circ} \mathrm{C}$ for $24 \mathrm{~h}$ using a laboratory drier Memmert ULE 500 (Germany) prior to further melt processing. The matrix pellets were physically mixed with $5,10,20$ and $30 \mathrm{wt} \%$ of the filler and then melt mixed using a co-rotating twin screw extruder ZAMAK EH-16.2D (Poland) operating at $120 \mathrm{rpm}$, a die temperature of $190{ }^{\circ} \mathrm{C}$. The extrudates were air-cooled, pelletized and dried at $70{ }^{\circ} \mathrm{C}$ for $24 \mathrm{~h}$ before further melt processing. The standardized samples were injection molded using an ENGEL ES 20/80HLS (Austria) injection molding machine $\left(T_{\text {injection }}=190{ }^{\circ} \mathrm{C}, T_{\text {mold }}=40^{\circ} \mathrm{C}\right.$, $\left.P_{\text {injection }}=72 \mathrm{MPa}, v_{\text {injection }}=75 \mathrm{~mm} / \mathrm{min}\right)$.

\section{Methodology of measurements}

\section{Mechanical properties}

To evaluate tensile modulus $E$, tensile strength $R m$ and elongation-at-break $\varepsilon$ values, a uniaxial tensile test was conducted using an Instron 4481 (USA) universal testing machine. According to PN EN ISO 527-2 standard recommendation, the crosshead speed was set to $50 \mathrm{~mm} /$ $\min$. The values of $E, R m$ and $\varepsilon$ were calculated by the Bluehill software.

Impact strength measurements of $15 \times 10 \times 4$ samples were performed according to DIN 53435 standard, using the Dynstat method. 15 samples of each kind were tested.

The hardness measurements (Brinell's method) were performed according to the PN-EN ISO 2039-1 standard using the KB Prüftechnik (Germany) apparatus. The hardness values are estimated on the basis of measurements of seven separate samples.

\section{SEM}

To examine the filler distribution in the polymeric matrix as well as the interfacial interactions between the HDPE and the LC particles, scanning electron microscopy (SEM) observations were conducted, using a Zeiss Evo 40 (Germany) microscope with an electron accelerating voltage of $12 \mathrm{kV}$. The pictures were digitally captured at a magnification of 500x.

\section{DSC}

Differential Scanning Calorimetry (DSC) measurements, which allow to evaluate the thermal properties of materials, were carried out using a Netzsch DSC 204F1 Phoenix apparatus (Germany). Material samples of $5.0 \pm 0.15 \mathrm{mg}$ were placed in aluminum crucibles with pierced lids, heated and cooled within the range of $20-210^{\circ} \mathrm{C}$ at a rate of $10{ }^{\circ} \mathrm{C} / \mathrm{min}$ and at an inert nitrogen atmosphere. The heating/cooling cycle was repeated to erase the influence of the thermal history on the composites' properties. The crystallization degree $X_{\mathrm{c}}$ was calculated according to the following equation:

$X_{\mathrm{c}}=\frac{\Delta H_{\mathrm{m}}}{(1-\varphi) \Delta H_{100 \% \mathrm{PE}}} \times 100$,

where $\Delta H_{\mathrm{m}}$ is melting enthalpy of the sample, $\Delta H_{100 \% \mathrm{PE}}$ is melting enthalpy corresponding to a $100 \%$ crystalline polyethylene $288 \mathrm{~J} / \mathrm{g}[19,20]$ and $\varphi$ is filler amount.

\section{Vicat softening temperature}

Vicat softening temperature (VST) analysis was operated by means of a CEAST HV3 apparatus (Italy). Measurements were carried out in an oil bath in accordance with the ISO 306 standard. Vicat softening temperature was determined in A50 measurement configuration, i.e., load $50 \mathrm{~N}$ and heating rate $50^{\circ} \mathrm{C} / \mathrm{h}$.

\section{DMTA}

Dynamic mechanical thermal analysis (DMTA) tests were performed using an Anton Paar MCR 301 rheometer (Austria) equipped with a torsion DMTA measuring tool. Investigations were carried out at a constant frequency of $1 \mathrm{~Hz}$ and a strain of $0.01 \%$. All samples were cooled down to $-135^{\circ} \mathrm{C}$ and heated up to $110^{\circ} \mathrm{C}$ with a temperature ramp of $2{ }^{\circ} \mathrm{C} / \mathrm{min}$.

\section{Water uptake}

To evaluate the susceptibility of water uptake, cleaned samples, three of each kind, were placed in distilled water in a closed container and then stored in room conditions for 48 days. The mass of each sample $m_{0}$ was established prior 
to the test and then every specimen would be periodically removed from the water to determine its current mass $m_{1}$. The moisture absorption level $M$ was calculated according to Eq. (2):

$M=\frac{m_{1}-m_{0}}{m_{0}} \times 100$.

\section{Statistics}

When calculating error bars for all of the graphs, confidence intervals were calculated at a significance level of 0.05 , using Student's $t$ distribution.

\section{Results and discussion}

\section{Mechanical properties}

The composites' mechanical properties are presented in Fig. 2a-d. As can be easily observed, the mechanical properties of LC-filled composites depended on the filler content. Tensile strength, elongation-at-break and Young's modulus values decrease depending on the LC concentration. A drop of tensile strength is typical for polymeric composites containing organic particulate fillers. A similar effect was described in the literature also in the case of waste fillers including brewer's spent grain [21], sunflower seed cake [22], milkweed seed cake [23] or coffee grounds [24] combined with different polymers. This outcome is usually an indicator of a poor compatibility between the filler and the polymeric matrix [24] and a weak adhesion between the two phases [22, 25].

The lack of interactions between PE and LC powder is caused by difference in their polarities [25]; unlike the non-polar polymer, the highly hygroscopic filler reveals a polar nature. Moreover, mechanical properties of the natural composites are strongly related not only to properties of the fillers, but also their geometry, orientation, and volumetric composition [26]. As it was observed, LC is a typical particle based filler with length to diameter ratio value below 2 . Therefore, when this value will be
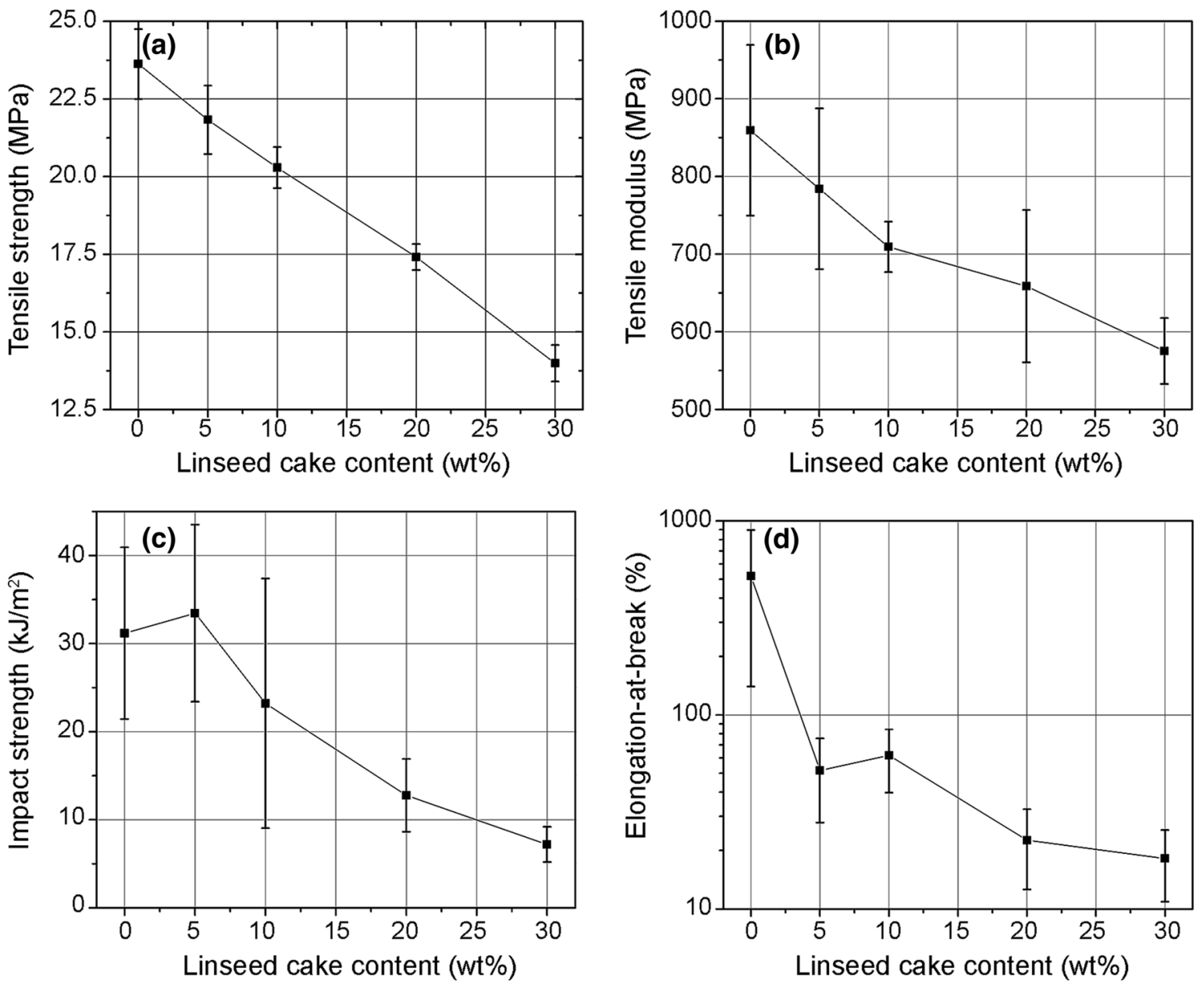

Fig. 2 Mechanical properties of the composites: a tensile strength, $\mathbf{b}$ tensile modulus, $\mathbf{c}$ impact strength, and $\mathbf{d}$ elongation-at-break 
considered with average particle size, it can be stated that the fiber length efficiency for factor stiffness takes values around 0.5 . That suggests that the used lignocellulosic particle based filler will not carry the maximum load that may be transferred by the filler materials in reference to their chemical structure [26].

Sieving process does not provide fibrous structures that may allow for effective stress transfer during load. A reduced flexibility, indicated by a decrease of elongation-at-break value, is also commonly detected for polymeric composites filled with waste particulate fillers. The addition of $5 \mathrm{wt} \%$ of LC only leads to a tenfold decrease of elongation-at-break value. Such a dramatic change can be also explained by stress concentration on filler particles, which act as internal notches $[27,28]$. As the affinity between the LC particles and the HDPE is low, cracks can propagate easily, which results in a composite's brittleness. A decrease in impact strength revealed by the composite samples also confirms the aforementioned behavior. Interestingly, samples containing $5 \mathrm{wt} \%$ of the filler revealed low elongation-at-break values and relatively high impact strength (no lower than in the case of neat HDPE). This can be caused by a poor dispersion of the LC characterized with irregular shape of the particles, also indicated by high confidence intervals [28].

As the filler does not disperse uniformly within the polymer, different results can be obtained in case of having various kinds of specimens. Modulus of elasticity is another mechanical property which decreases because of the filler addition. In case of natural particles-filled polymeric composites, an increase in Young's modulus is usually reported with accompanied decrease of elongation-at-break [27, 29]. In case of using of LC as filler with high linseed oil content, both mechanical parameters decreased with increasing amount of the filler.

Figure 3 presents photos of the samples after tensile test, it can be seen that composites containing up to $10 \mathrm{wt} \%$ exhibit necking effect, while composites filled with 20 and $30 \mathrm{wt} \%$ of the LC fractured in the brittle way. Drop of stiffness can be explained by the presence of oil within the filler, which can act as an internal lubricating agent facilitating the macromolecules' mobility [30]. A similar effect was reported in the case of different composites filled with agricultural waste fillers such as pistachio shell-filled polyethylene [31], date seed powder filled biopolymers [29] or in the case of rapeseed cake-filled polyurethane foams [32]. Plasticizing effect caused by migrating oil to polyethylene dominates the reinforcing effect of the lignocellulosic particles on the polymeric matrix. Moreover, as it was observed in SEM micrographs part of the linseed oil migrates to polymeric matrix and is collected at interfacial region. This phenomenon probably provided a decrease in the adhesion between polymer and the filler and reduced the ability of the effective stress transfer by the composite.

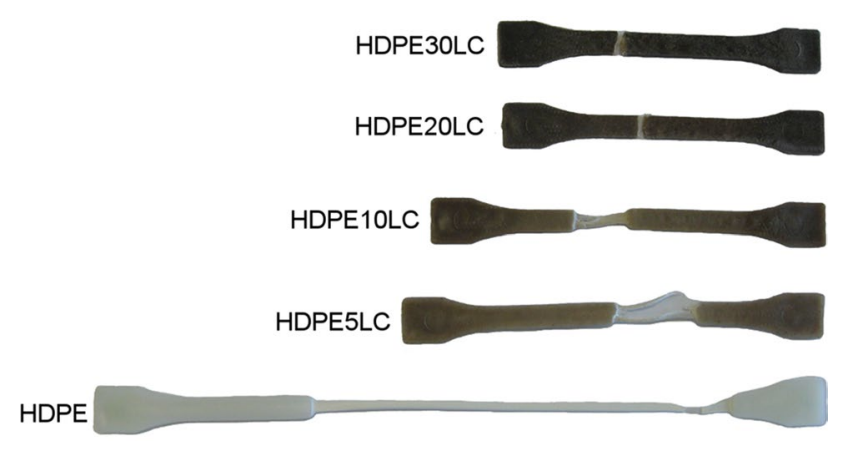

Fig. 3 HDPE and composite samples after tensile test

\section{Microstructure}

SEM micrographs of the cryofractured composites' surfaces and LC are shown in Fig. 4. An observation of the fracture surface can explain the influence of the filler particles on the mechanical properties of the composites. Moreover, it can provide useful information about the interactions between the matrix and the embedded particles.

When the neat HDPE is fractured in the brittle state, a typical smooth surface can be observed, whereas in the case of the composites, distinct cracks propagate from the filler particles. Furthermore, a visible gap on the interface between the filler and the matrix indicates a low level of adhesion and weak interactions between the two phases. Some of the particles are even pulled out of the polymer due to the fracture. LC is not dispersed uniformly within the polyethylene matrix; in fact, when the filler content exceeds $10 \mathrm{wt} \%$, LC aggregated and formed clusters (marked by red circles).

All of the aforementioned factors contribute to the fact that the fracture surface was not even and smooth. The findings based on the SEM observations were in good agreement with the results of the mechanical tests. The interactions between the polar, the hydrophilic filler and the hydrophobic polymer are not sufficient to provide a good interfacial adhesion. As the LC particles tend to aggregate, therefore, they may constitute points of stress concentration, from which the cracks propagate.

\section{Thermal properties}

Thermograms obtained during the second heating and the first cooling of the DSC measurements are shown in Fig. 5. Melting and crystallization temperatures $\left(T_{\mathrm{m}}\right.$ and $T_{\mathrm{c}}$, respectively) as well as melting enthalpy values $\left(\Delta H_{\mathrm{m}}\right)$ and crystallinity level $\left(X_{\mathrm{c}}\right)$ are presented in Table 1.

As can be seen, melting and crystallization temperatures of the composites were changed in comparison with the pure HDPE. In the case of $T_{\mathrm{m}}$, a small shift towards lower 

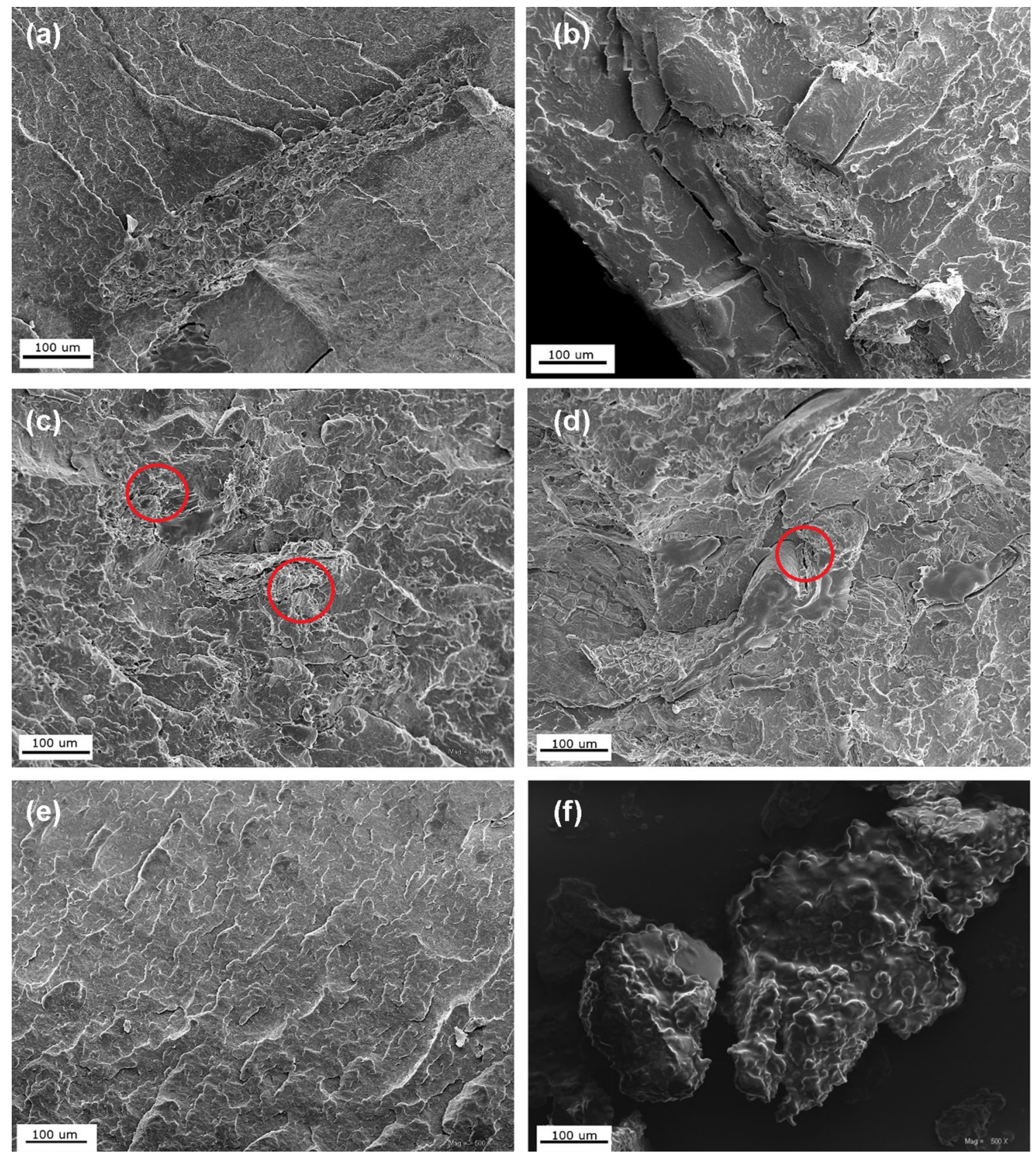

Fig. 4 SEM micrographs of fracture surfaces of the composites with: a 5, b 10, c 20, and $\mathbf{d} 30 \mathrm{wt} \% \mathrm{LC}$, e HDPE samples and $\mathbf{f}$ linseed cake particles (magnification $\times 500$ )

temperatures can be observed, especially if the filler content exceeds $20 \mathrm{wt} \%$. Similar results have already been reported in the case of composites containing different agricultural waste fillers with residual fat, including pistachio shells [31], milkweed cake [24], dried distillers grains [30] or sunflower seed cake [23].

The decrease in the composites melting temperature in comparison with pure HDPE can be explained by the creation of amorphous domains made of vegetable oil migrating from the filler to the polyethylene matrix, which provides a loose crystal structure characterized with a lower heat resistance capacity [33]. The influence of the organic filler on the crystallization of polyethylene was observed on the changes in the crystallization temperature, melting enthalpy and crystallinity level. The addition of LC to HDPE caused a negligible change in $T_{\mathrm{c}}$ toward higher temperatures and decrease in the melting enthalpy.

Despite an insignificant increase in the crystallization temperature, it can be assumed that LC improved the crystallization of the polyethylene matrix. The crystallinity level 

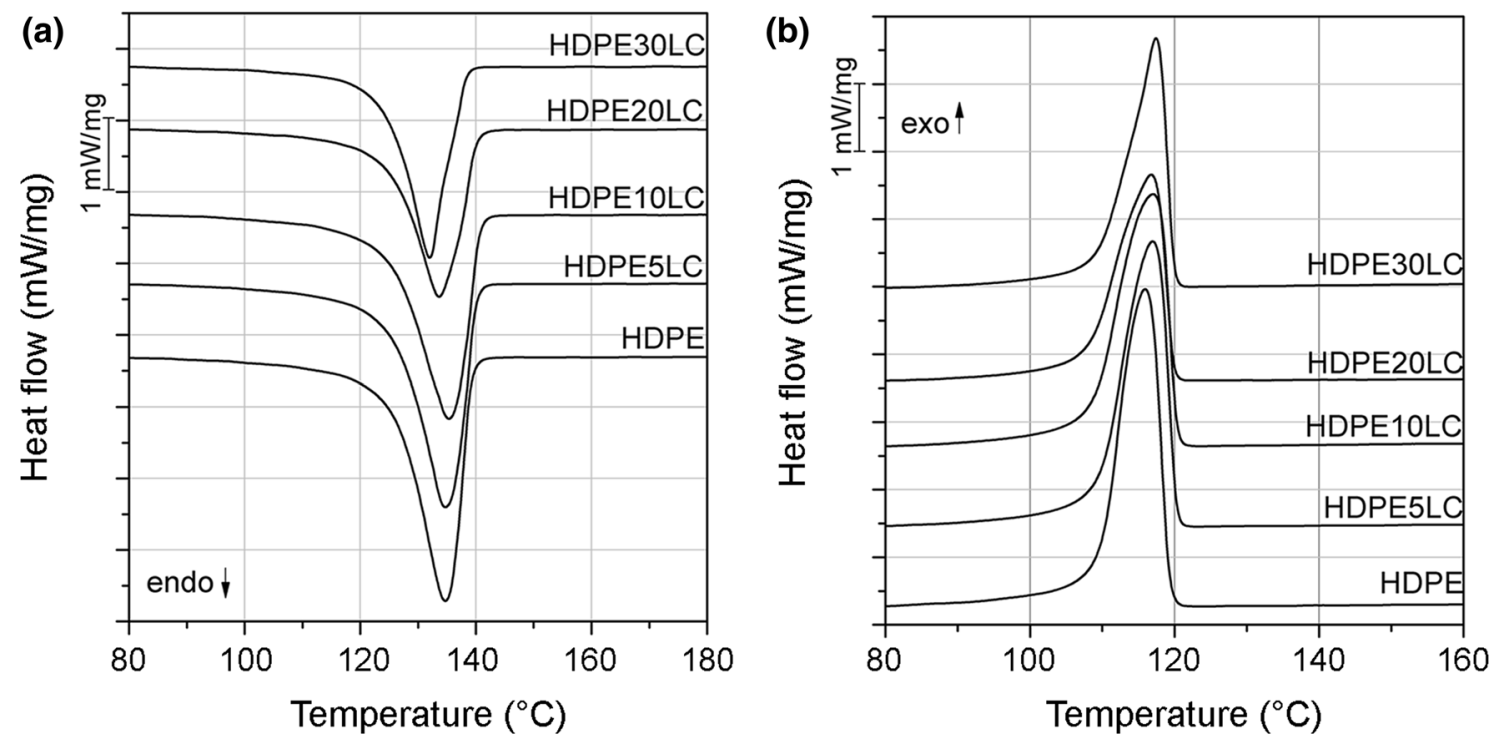

Fig. 5 DSC thermograms obtained during: a second heating and $\mathbf{b}$ first cooling cycles

Table 1 Melting and crystallization temperatures, melting enthalpy and crystallization degree values of the HDPE and HDPE-LC composites

\begin{tabular}{lllll}
\hline Sample code & $T_{\mathrm{m}}\left({ }^{\circ} \mathrm{C}\right)$ & $T_{\mathrm{c}}\left({ }^{\circ} \mathrm{C}\right)$ & $\Delta H_{\mathrm{m}}(\mathrm{J} / \mathrm{g})$ & $X_{\mathrm{c}}(\%)$ \\
\hline HDPE & 134.7 & 116.9 & 206.6 & 71.7 \\
HDPE5LC & 134.7 & 117.1 & 203.5 & 74.4 \\
HDPE10LC & 135.3 & 117.3 & 197.7 & 76.3 \\
HDPE20LC & 132.8 & 117.3 & 167.0 & 72.5 \\
HDPE30LC & 132.0 & 117.4 & 171.7 & 85.2 \\
\hline
\end{tabular}

calculated on the basis of the melting enthalpy increased significantly from $71.7 \%$ for pure HDPE up to $85.2 \%$ in the case of the composite with the highest content of the natural filler. Similar nucleation efficiency was observed by $\mathrm{Li}$ et al. [34] in the case of HDPE-bamboo fiber composites. It can be stated that the modification of thermal properties determined by DSC is the result of the complex chemical structure of LC.

In reference to the literature, lignocellulosic particles dispersed in a polymeric matrix do not provide an increase in the HDPE crystallization rate [35]. Despite the developed surface of the LC particles, their big sizes exclude them as effective nucleating centers for HDPE. What's more, LC particles were weakly adhered to the matrix therefore, they did not restrain the possibilities of the polymeric chains movements [36]. We can assume that, at an elevated temperature, there is a migration of the linseed oil from the filler to the polymer matrix. Linseed oil characterized with a low molecular weight [37] and dispersed in the polyethylene matrix acted as a nucleating agent that provided additional nuclei and induced the crystallization process, promoting polyethylene's crystal growth [33].

\section{Vicat softening temperature}

The values of Vicat softening temperature (VST) measured for the composites and the neat HDPE are presented in Fig. 6. It can be observed that adding LC reduced the softening temperature. These results are in good agreement with the DSC analysis, which confirmed a decrease of the melting temperature of the LC-filled samples. The incorporation of LC into HDPE caused a gradual reduction of VST, whose intensity varies with the increasing content of natural filler. A 25\% reduction of VTS was observed for HDPE30LC $\left(50.9^{\circ} \mathrm{C}\right)$ compared to unmodified $\operatorname{HDPE}\left(66.6^{\circ} \mathrm{C}\right)$.

Usually, the modification of polyolefins with natural fillers results in an improvement of the composites' softening temperature and thermomechanical stability [38, 39]. The results described in the present study are opposed to this mechanism. The drop of VTS caused by the modification of HDPE with LC may be explained by the presence of linseed oil within the filler, which acts as an internal lubricant. Linseed oil migrates to the polymeric matrix and creates amorphous domains, dispersed at both macroscopic and molecular levels, which suppress the possible reinforcing mechanism, caused by lignocellulosic fraction of LC, hence the plasticizing effect of the post-agricultural waste filler.

The decrease in VST may be correlated to the samples' hardness values which are also presented in Fig. 6. As the hardness of the HDPE composites lowered along with the growing LC content, in case of the VST measurements, the testing needle penetrated the surface of the specimens at a 


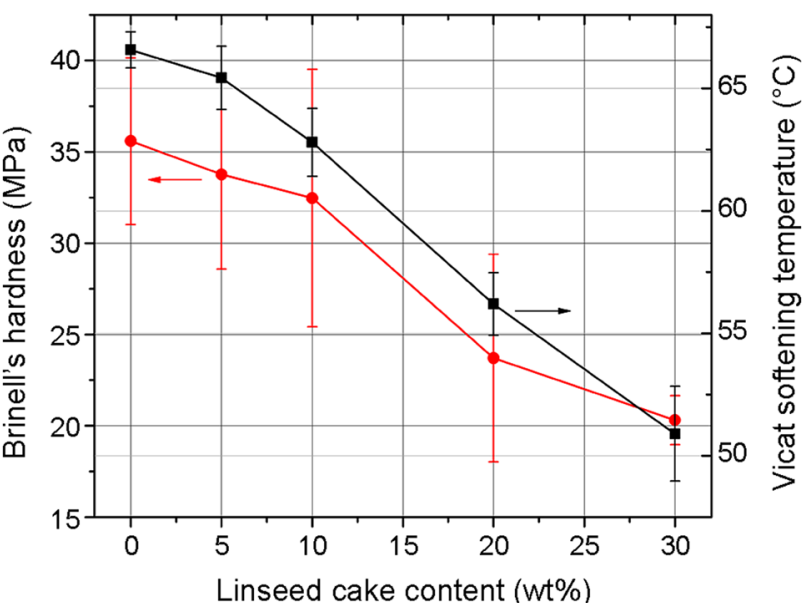

Fig. 6 Plots of Vicat softening temperature values and Brinell's hardness for the composite samples

lower temperature, in comparison with the neat polymeric matrix. The reduction of VST in the case of polymeric composites filled with post-agricultural waste fillers was in fact caused by the decrease in their hardness and did not necessarily indicate a change of their thermal stability. Nevertheless, both phenomena can be explained by the plasticizing effect of LC as well as low hardness of the filler which volumetric amount in composites provided the overall decrease of this resistance for point-type load indentation.

\section{Thermomechanical properties}

Dynamic mechanical thermal analysis (DMTA) is a powerful measuring technique that allows indirectly assessing to molecular changes in modified polymeric materials or interfacial interactions between components of polymeric blends or composites [40]. The results of the DMTA are presented in Fig. 7 where, the dependence of storage modulus $\left(G^{\prime}\right)$, loss modulus $\left(G^{\prime \prime}\right)$ and damping factor $(\tan \delta)$ on temperature are presented for each of the aforementioned parameters, separately. The application of DMTA in reference to the previously discussed results allows for understanding the complex effects of the polyethylene modification by LC.

During the course of the dynamic analysis realized as a function of temperature, three polyethylene relaxations can be denoted: $\alpha, \beta$ and $\gamma$. $\alpha$-relaxation, observed for highdensity polyethylene around $50{ }^{\circ} \mathrm{C}$, is ascribed to the crystalline phase of the polymer. $\beta$-relaxation, observed usually between -40 and $-10{ }^{\circ} \mathrm{C}$, is related to $\mathrm{PE}$ branched amorphous structures, while $\gamma$-relaxation, observed around $-110^{\circ} \mathrm{C}$, is caused by short-range segmental motions of the amorphous polyethylene [40, 41].

In the case of a modification of HDPE by LC, we suppose the overall modifying effect is based on three different

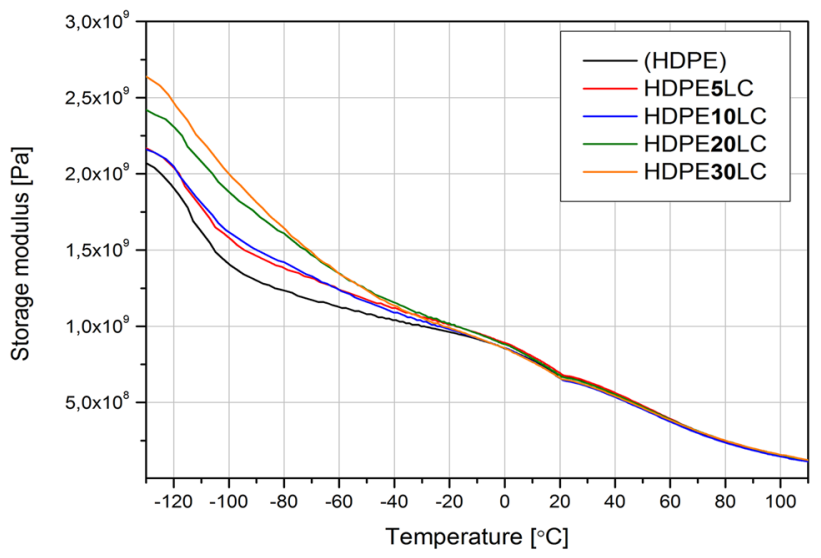

(a)

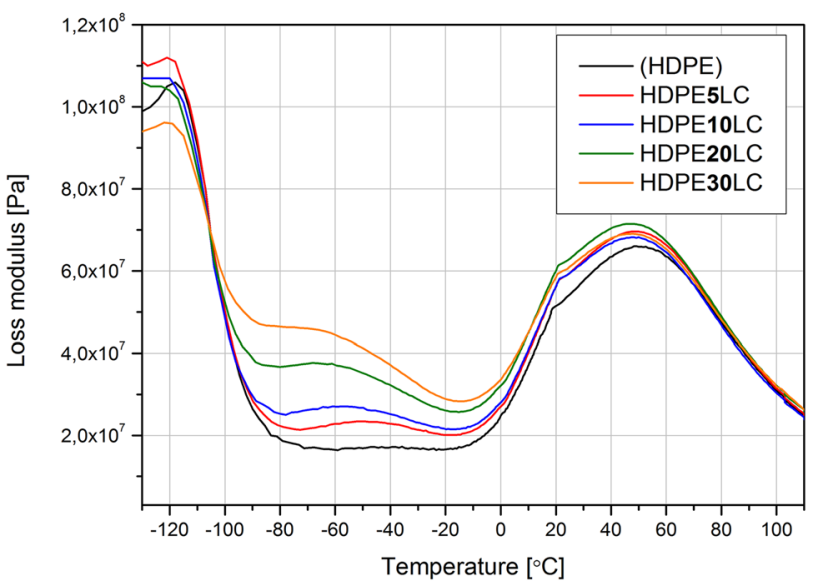

(b)

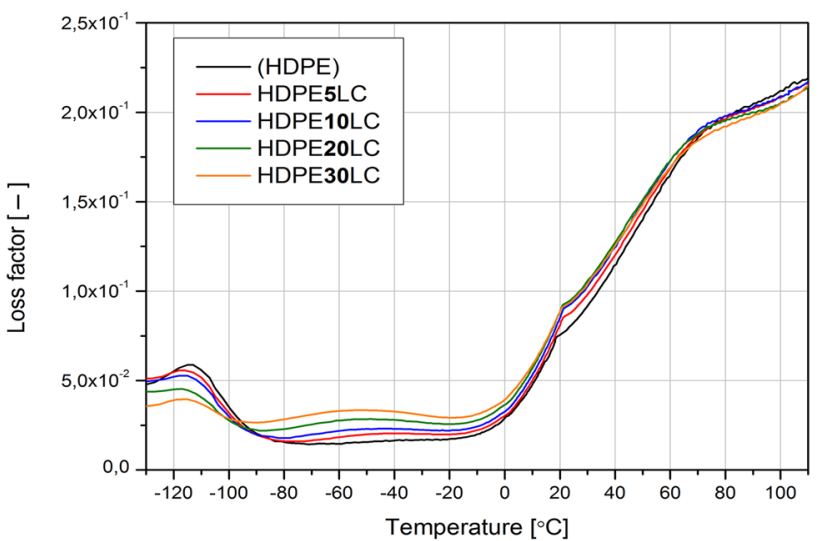

(c)

Fig. 7 DMTA curves: a storage modulus $\left(G^{\prime}\right)$, b loss modulus $\left(G^{\prime \prime}\right)$ and $\mathbf{c}$ loss factor $(\tan \delta)$ vs. temperature for HDPE and HDPE-LC composites

mechanisms occurring simultaneously. The first is based on lignocelluloses parts of organic waste filler strengthening the polymeric matrix. The second phenomenon is based on 
a weak interfacial bonding between the polymeric matrix and the filler, resulting from different polarities of both composite ingredients. The last one is connected with the presence and migration of linseed oil from organic waste filler, which simultaneously may cause nucleating effects and/or the creation of amorphous plasticizing domains, also in the interfacial region.

The measurements of the dynamic storage modulus are usually in good agreement with the measurements of the elastic modulus and material stiffness. We can observe that incorporating agricultural waste filler into HDPE provoked significant changes in $G^{\prime}$ behavior. The higher the amount of organic filler, the higher storage modulus values were observed in the range of temperatures between -120 and $-40{ }^{\circ} \mathrm{C}$. Interestingly, the modification efficiency is temperature-dependent. Differences in $G^{\prime}$ values at temperatures below $-20^{\circ} \mathrm{C}$ between pure HDPE and composite samples might be connected with linseed oil solidification, which according to literature was about $-10{ }^{\circ} \mathrm{C}$ [42].

After reaching $\beta$ relaxation, the difference between the considered materials series and the pure polyethylene became negligible. Therefore, the improvement of the material stiffness might be attributed to the nucleating ability rather than the reinforcing effect caused by lignocellulosic material dispersed in the polymeric matrix. This phenomenon can be confirmed by the negligible difference between $G^{\prime}$ values of the pure HDPE and composite materials at room and elevated temperatures. In case of effective reinforcing effect caused by the presence of rigid structures of the filler, the increased storage modulus values should be observed in the whole considered temperature range [3, 43]. It cannot be excluded that the decrease of linseed oil viscosity related to the temperature increase [42] resulted in more intensive migration of the oil from the filler. It provided suppression of the potential reinforcing effects induced by incorporation of rigid lignocellulosic structures, which was observed as an increase in $G^{\prime}[43,44]$.

The second discussed dynamic parameter is the loss modulus, which is a measure of energy dissipated due to mechanical relaxation. Therefore, its analysis is useful in case of describing the mechanisms of macromolecular internal motions. In the range of two relaxations ascribed the movements of the amorphous phase, i.e., long $(\beta)$ and short $(\gamma)$ chain branches [40], there are different behavior of the composites modified with LC on $G^{\prime \prime}$ vs. $T$ and $\tan \delta$ vs. $T$ which can be observed on DMTA curves.

With an increasing content of the crude oil-rich LC in HDPE-based composites, the intensity of tan $\delta$ maximum value increased in the range of $\beta$-relaxation, which was the effect of the increase in the dissipated energy. In the considered temperature range $\left(-80\right.$ to $\left.-20{ }^{\circ} \mathrm{C}\right)$ the previously mentioned increase of $G^{\prime}$ was accompanied by a gradual decrease of $T_{\mathrm{g}}$ with an increasing $G^{\prime \prime}$ intensity. It may be attributed to the plasticizing effect of the linseed oil amorphous phases [45], which despite the presence of a high amount of lignocellulosic structures in polyethylene are keeping the damping ability of the dynamic mechanical load.

There occurs an inversion in the composites dynamic response in the range of $\gamma$-relaxation in comparison with the behavior observed at $\beta$-relaxation. A decrease in glass transition temperature, measured as a local maximum in curve of $\tan \delta$ vs. $T$, with simultaneously increased composites' stiffness, confirms the aforementioned possibility of linseed oil migration at a molecular level. According to Woo et al., the decreased intensity of $\gamma$-relaxation observed in the composites containing the highest amount of the filler (i.e., 20 and $30 \mathrm{wt} \%$ ) may be attributed to a lowered content of amorphous phase in polyethylene [40].

Some changes between pure HDPE and composites were denoted also at $\alpha$-relaxation region. As has been already mentioned, $\alpha$-relaxation is a representative of crystalline phase and its related mobility in the crystal domains interior [41]. For all composites, the $\alpha$ peak of $G^{\prime \prime}$ curve shifts to lower temperature values, which in reference to the interpretation of Popli et al. [46] may be attributed to a reduced lamellar thickness in the case of composite materials, which is in good agreement with DSC investigations.

\section{Moisture absorption}

The changes in moisture content of the samples as a function of time are presented in Fig. 8. The presence of highly hydrophilic lignocellulosic filler causes an increase in the moisture absorption. A similar behavior of polymeric composites containing natural-based fillers has already been reported [22, 30, 31, 47]. However, it should be noticed that for the composites containing up to $20 \mathrm{wt} \%$ of LC, the amount of absorbed moisture does not exceed $1 \mathrm{wt} \%$.

Application of hydrophobic HDPE as the matrix of the composites (which absorbs no more than $0.03 \mathrm{wt} \%$ of water) vastly limits the possibilities of the water uptake. Only in the case of samples containing a high amount of the plant-based filler (30 wt \%), moisture absorption grows rapidly. According to the SEM analysis, it can be presumed that a significant increase in the composites' water absorption ability in the case of materials containing 20 and $30 \mathrm{wt} \%$ of the filler happens as a result of structural changes. Composites with LC content below $20 \mathrm{wt} \%$ were characterized with a better dispersion of organic particles in the polymeric matrix and a lower possibility of the presence of the particles uncovered by polyethylene at the samples surface.

There is an increase in water absorption resulting from the hydrophilic behavior of the unimpregnated LC particles that are suspected to contact with water. In the case of the composite filled with $30 \mathrm{wt} \%$ of LC, organic particles create 


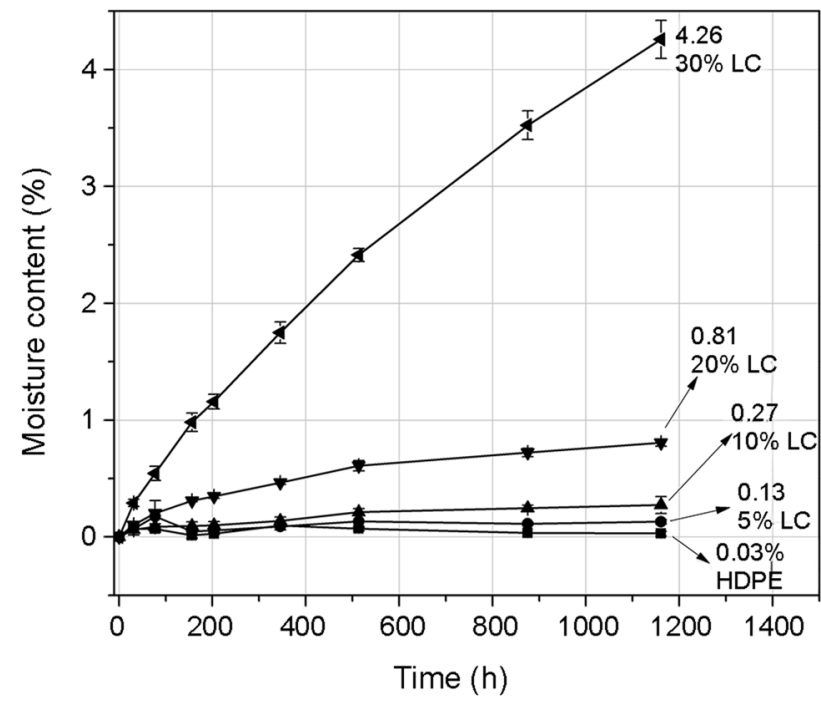

Fig. 8 Changes of moisture content absorbed by the composite samples as a function of time

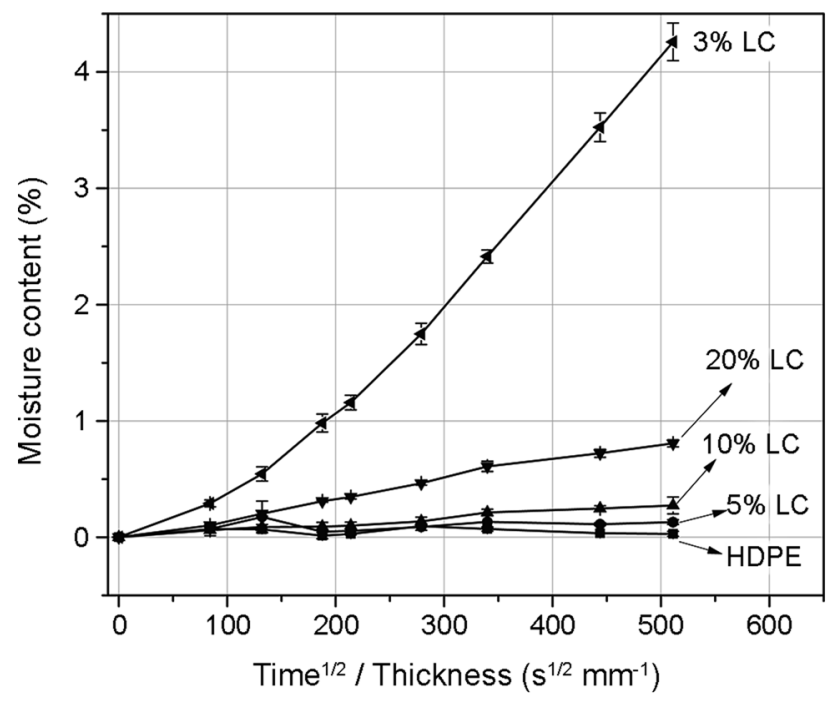

Fig. 9 Water absorption isotherms for HDPE and HDPE-LC composites

agglomerated structures in the whole sample volume, which due to mutual contact allows for water absorption with an intensity that adjusts to the amount of filler in the composite.

In Fig. 9 water absorption isotherms of the polyethylene and polyethylene-based composites are presented. The higher the amount of the filler, the higher was the water absorption rate. It should be mentioned, that none of the considered materials revealed equilibrium state after immersion in water. Therefore, according to results presented by Najafi et al. [48] who discussed water absorption of polyethylene composites filled with different natural fibers, it can be stated that diffusion coefficients could not be calculated [48].

According to the literature this effect is related to a phenomenon of creation of plastic coating around the hydrophilic particles of the filler and at the surface of injection molded samples, which caused lower water absorption intensity [48]. The differences between samples may be attributed to the fact that, despite hydrophilic filler particles were coated by polymer which created closed pores around most of them, high volumetric amount of the LC results in the creation of the aggregates and creates locally lack of full impregnation by the hydrophobic polyethylene matrix [31]. It may be assumed that the HDPE composites filled with LC with a filler amount exceeding $20 \mathrm{wt} \%$ should not be used in water environment, yet moisture absorption does not limit their application in room conditions.

\section{Conclusion}

High density polyethylene-based composites filled with a post-agricultural waste filler have been successfully manufactured. HDPE-LC composites revealed lower melting temperature and higher crystallization temperature in comparison with the neat HDPE. Therefore, their processing may be more energy and time efficient. It was found that the complicated chemical structure of the LC containing high amount of crude oil, the modification effect on polyethylene became much more complex than in the case of standard lignocellulosic fillers. The application of DSC and DMTA measurements allow to describe LC's nucleation ability, the increase of the composites crystallinity in comparison with pure HDPE was $13.5 \%$. The plasticizing effect observed in the mechanical, as well as static and dynamic thermomechanical analysis was attributed to crude oil migrating from filler to polymeric matrix and interfacial region during melt processing and further conditioning of the composite materials. According to complex material analysis it can be stated that optimum amount of the filler for production of HDPEbased composites filled with LC is $10 \mathrm{wt} \%$. Incorporation of $10 \mathrm{wt} \%$ of LC allowed for lower of final material price in reference to pure polymer, without significant reduction of mechanical properties which may exclude their industrial application. A low affinity between the filler and the matrix, as well as a high moisture absorption level, may be disadvantageous in certain applications. The highest amount of the filler, which does not create a risk of uncontrolled deformations during the use of final product due to significant increase of water absorption ability was $10 \mathrm{wt} \%$. The presented results exhibit the complicated influence that agricultural waste characterized with high fat content has on the overall behavior of the polyethylene-based composites, 
which can find an application in polymer processing industry as a filler for low-strength polymeric composites.

Acknowledgements This work was supported by the Ministry of Science and Higher Education of Poland under the Grant no. 02/25/ DSMK/4445. The authors would like to thank Mrs. Joanna Szulc for realization of oil content analysis using the Soxhlet method.

Open Access This article is distributed under the terms of the Creative Commons Attribution 4.0 International License (http://creativeco mmons.org/licenses/by/4.0/), which permits unrestricted use, distribution, and reproduction in any medium, provided you give appropriate credit to the original author(s) and the source, provide a link to the Creative Commons license, and indicate if changes were made.

\section{References}

1. Geissdoerfer M, Savaget P, Bocken NMP, Hultink EJ (2017) The Circular Economy - a new sustainability paradigm? J Clean Prod 143:757-768

2. Ganster J, Erdmann J, Fink H-P (2013) Biobased composites. Polimery-W 58:423-434

3. Salasinska K, Ryszkowska J (2015) The effect of filler chemical constitution and morphological properties on the mechanical properties of natural fiber composites. Compos Interfaces 22:39-50

4. Kijeński J, Kijeńska M, Osawaru O (2016) Plant fibers as alternatives to mineral fillers in thermoplastic composites-Ford's vision or Al Gore's? Polimery-W 7-8:467-473

5. Le Duigou A, Davies P, Baley C (2011) Environmental impact analysis of the production of flax fibers to be used as composite material reinforcement. J Biobased Mater Bioenergy 5:153-165

6. Mridula D, Barnwal P, Singh KK (2015) Screw pressing performance of whole and dehulled flaxseed and some physico-chemical characteristics of flaxseed oil. J Food Sci Technol 52:1498-1506

7. 2016 Annual Statistics (2017) Meals production, imports, exports and consumption -fediol. http://www.fediol.be. Accessed 06 Feb 2017

8. Jóźwik A, Strzałkowska N, Markiewicz-Kęszycka M, Krzyżewski J, Lipińska P, Rutkowska J, Wróblewska B, Klusek J, Cooper RG (2016) Effects of replacing rapeseed cake with linseed cake in a corn-grass silage-based diet for milking cows. Anim Sci Pap Rep 34:129-142

9. Sielicka M, Małecka M (2017) Enhancement of oxidative stability of flaxseed oil through flaxseed, evening primrose and black cumin cake extracts. J Food Process Preserv 41:13070

10. Popa VM, Gruia A, Raba DN, Dumbrava D, Moldovan C, Bordean D, Mateescu C (2012) Fatty acids composition and oil characteristics of linseed (Linum Usitatissimum L.) from Romania. J Agroaliment Proc Technol 18:136-140

11. Zuk M, Richter D, Matuła J, Szopa J (2015) Linseed, the multipurpose plant. Ind Crops Prod 75:165-177

12. Tayde S, Patnaik M, Bhagt SL, Renge VC (2011) Epoxidation of vegetable oils: a review. Int J Adv Eng Technol 2:491-501

13. Chieng BW, Ibrahim NA, Then YY, Loo YY (2014) Epoxidized vegetable oils plasticized poly(lactic acid) biocomposites: mechanical, thermal and morphology properties. Molecules 19:16024-16038

14. Malewska E, Bąk S, Kurańska M, Prociak A (2016) The effect of various rapeseed oil-based polyols on selected properties of flexible polyurethane foams. Polimery-W 61:799-806
15. Ali F, Chang Y-W, Kang SC, Yoon JY (2009) Thermal, mechanical and rheological properties of poly(lactic acid)/epoxidized soybean oil blends. Polym Bull 62:91-98

16. Al-Mulla EAJ, Yunus WMZW, Bt Ibrahim NA, Ab Rahman MZ (2010) Properties of epoxidized palm oil plasticized polytlactic acid. J Mater Sci 45:1942-1946

17. Borysiak S (2013) Fundamental studies on lignocellulose/polypropylene composites: effects of wood treatment on the transcrystalline morphology and mechanical properties. J Appl Polym Sci 127:1309-1322

18. Ashori A (2008) Wood-plastic composites as promising green-composites for automotive industry. Bioresour Technol 99:4661-4667

19. Wunderlich B (1973) Macromolecular physics: crystal structure, morphology, defects. Academic, New York

20. Khonakdar HA, Morshedian J, Wagenknecht U, Jafari SH (2003) An investigation of chemical crosslinking effect on properties of high-density polyethylene. Polymer 44:4301-4309

21. Hejna A, Formela K, Saeb MR (2015) Processing, mechanical and thermal behavior assessments of polycaprolactone/agricultural waste biocomposites. Ind Crops Prod 76:725-733

22. Ayrilmis N, Kaymakci A, Ozdemir F (2013) Sunflower seed cake as reinforcing filler in thermoplastic composites. J Appl Polym Sci 129:1170-1178

23. Finkenstadt VL, Liu C-K, Evangelista R, Liu LS, Cermak SC, Hojilla-Evangelista M, Willet JL (2007) Poly(lactic acid) green composites using oilseed coproducts as fillers. Ind Crops Prod 26:36-43

24. Moustafa H, Guizani C, Dufresne A (2017) Sustainable biodegradable coffee grounds filler and its effect on the hydrophobicity, mechanical and thermal properties of biodegradable PBAT composites. J Appl Polym Sci 134:44498. https://doi.org/10.1002/ app.44498

25. Finkenstadt VL, Mohamed AA, Biresaw G, Willet JL (2008) Mechanical properties of green composites with polycaprolactone and wheat gluten. J Appl Polym Sci 110:2218-2226

26. Shah DU (2013) Developing plant fibre composites for structural applications by optimizing composite parameters: a critical review. J Maters Sci 48:6083-6107

27. Fuqua MA, Chevali VS, Ulven CA (2013) Lignocellulosic byproducts as filler in polypropylene: comprehensive study on the effects of compatibilization and loading. J Appl Polym Sci 127:862-868

28. Švehlová V, Polouček E (1987) About the influence of filler particle size on toughness of filled polypropylene. Angew Makromol Chem 153:197-200

29. Mittal V, Chaudhry AU, Matsko NB (2014) "True" biocomposites with biopolyesters and date seed powder: mechanical, thermal, and degradation properties. J Appl Polym Sci 131:40816. https:// doi.org/10.1002/app.40816

30. Tisserat BH, Reifschneider L, O'Kuru RH, Finkenstadt VL (2013) Mechanical and thermal properties of high density polyethylenedried distillers grains with solubles composites. Bioresources 8:59-75

31. Salasinska K, Polka M, Gloc M, Ryszkowska J (2016) Natural fiber composites: the effect of the kind and content of filler on the dimensional and fire stability of polyolefin-based composites. Polimery-W 61:255-265

32. Paciorek-Sadowska J, Czupryński B, Borowicz M, Liszkowska J (2015) New polyurethane materials containing biofiller. PolimeryW 60:586-591

33. Chen J, Wang X, Liu W (2014) Crystallization kinetics of polyethylene/paraffin oil blend sheets formed by thermally induced phase separation with different molecular weights of polyethylene. J Therm Anal Calorim 118:1649-1661 
34. Li Y, Du L, Zhang Z, Wu Q (2015) High-density polyethylene and heat-treated bamboo fiber composites: nonisothermal crystallization properties. Int J Polym Sci 2015:658584. https://doi. org/10.1155/2015/658584

35. Zou P, Tang S, Fu Z, Xiong H (2009) Isothermal and non-isothermal crystallization kinetics of modified rape straw flour/highdensity polyethylene composites. Int J Therm Sci 48:837-846

36. Gaikwad P, Mahanwar P (2017) Studies in effect and synthetic and natural microfibers on properties of high-density polyethylenereinforced composite. Polym Plast Technol Eng 56:131-140

37. Gay PJ (1933) The determination of molecular weight of linseed oil and polymerides. J Chem Technol Biotechnol 52:703-705

38. Kuciel S, Jakubowska P, Kuźniar P (2014) A study on the mechanical properties and the influence of water uptake and temperature on biocomposites based on polyethylene from renewable sources. Compos Part B Eng 64:72-77

39. Taşdemir M, Biltekin H, Caneba GT (2009) Preparation and characterization of LDPE and PP-wood fiber composites. J Appl Polym Sci 112:3095-3102

40. Woo L, Ling MTK, Westphal SP (1996) Dynamic mechanical analysis (DMA) and low temperature impact properties of metallocene polyethylenes. Thermochim Acta 272:171-179

41. Khanna YP, Turi EA, Taylor TJ (1985) Dynamic mechanical relaxations in polyethylene. Macromolecules 18:1302-1309
42. Skrzyńska E, Matyja M (2011) Comparison of the physicochemical properties of select natural fats and their methyl esters. Chemik 65:923-935

43. Liu H, Wu Q, Han G, Yao F, Kojima Y, Suzuki S (2008) Compatibilizing and toughening bamboo flour-filled HDPE composites: mechanical properties and morphologies. Compos Part A Appl Sci 39:1891-1900

44. Poletto M (2017) Mechanical, dynamic mechanical and morphological properties of composites based on recycled polystyrene filled with wood flour wastes. Maderas Ciencia y tecnología 19:433-442

45. Ljungberg N, Wesslén B (2002) The effects of plasticizers on the dynamic mechanical and thermal properties of poly(lactic acid). J Appl Polym Sci 86:1227-1234

46. Popli R, Glotin M, Mandelkern L, Benson RS (1984) Dynamic mechanical studies of $\alpha$ and $\beta$ relaxations of polyethylenes. J Polym Sci Polym Phys Ed 22:407-448

47. Tasdemir M (2017) Effects of olive pit and almond shell powder on polypropylene. Key Eng Mater 733:65-68

48. Najafi SK, Tajvidi M, Chaharmahli M (2006) Long-term water uptake behavior of lignocellulosic-high density polyethylene composites. J App Polym Sci 102:3907-3911 